ORIGINAL PROF-2018

\title{
SERUM PROSTATE SPECIFIC ANTIGEN (PSA);
}

In normal subjects and patients of benign prostatic hyperplasia and carcinoma prostate.

\section{Dr. Zehra Naz, Dr. Saadia Anjum, Dr. Mehdi Raza.}

ABSTRACT... Objective: To study correlation between age-linked serum prostate specific antigen (PSA) levels in normal subjects and patients of benign prostatic hyperplasia (BPH) and carcinoma prostate (CaP). Data source: OPDs. Study design: Case-control study. Setting: SIUT; Karachi Study duration: Six months. Methodology: 250 subjects were enrolled for the study and 93 were finally selected (31 each, representing the normal, BPH and CaP groups). Subjects 40 years of age and above were included and those with any urinary tract disorder or those under treatment with 5-á-reductase inhibitors were excluded. Each group was divided into four sub-groups of ages $40-49,50-59,60-69$ and 70 and above years. AxSYM total PSA (tPSA) assay ${ }^{\circledR}$ was used for serum PSA estimation. Values were expressed as mean and standard error of mean and Fischer's test, students' t test and correlation coefficient were used to determine significance and for comparison of data. Results: There was a no significant difference in PSA levels in all age groups when normals were compared with BPH cases. PSA levels were significant in normal as compared to CaP cases and BPH as compared to CaP. Conclusions: No significant correlation between age-linked serum PSA levels in normal subjects and patients of BPH and CaP could be established. The study, however, found a trend of declining PSA levels at the age of 70 years and above.

Key words: BPH = Benign Prostatic Hyperplasia, CaP = Carcinoma prostate, PSA = Prostate Specific Antigen, PPSA = Prostate specific antigen-total.

\section{Article Citation}

$\checkmark \quad \quad$ Naz Z, Anjum S, Raza M. Correlation between age-linked serum prostate specific antigen (PSA) in normal subjects and patients of benign prostatic hyperplasia and carcinoma prostate. Professional Med J Feb 2013;20(1):017-022.

\section{INTRODUCTION}

As carcinoma prostate (CaP) has become the commonest cancer ${ }^{1}$ and benign prostatic hyperplasia (BPH), the commonest disease of advancing age, in Pakistani men, the need for screening men for prostate disease has increased. Prostate specific antigen is the single best screening marker $^{2}$ available for the diagnosis of these two diseases along with digital rectal examination (DRE) and transrectal ultrasonography (TRUS).

PSA was isolated by Wang et al ${ }^{3}$ in 1979 and is specific for prostatic tissue ${ }^{4}$. Serum PSA levels depend on epithelial volume and mean PSA level has been found to be $1.27 \mathrm{ng} / \mathrm{mL} / \mathrm{cm}^{3,5}$. Due to this relationship, whenever there is hypertrophy of prostate, either benign or malignant, there is a rise in PSA level. However, despite being the 'most useful tumor marker ${ }^{\prime}{ }^{6}$ great variability and overlap exists in the PSA levels observed in $\mathrm{CaP}$ and $\mathrm{BPH}$. Up to $4 \mathrm{ng} / \mathrm{mL}$ is considered as the normal limit'. Several researchers on the subject have reported varying PSA levels in different populations (towards the lower limit in certain populations while at the upper limit of the reference range in others). We did not come across any research focusing on PSA levels in normal subjects and BPH and $\mathrm{CaP}$ cases, in different age groups of Pakistani men, which could have given expected PSA levels in our population, and could be used as reference for the diagnosis of these diseases in our patients.

Therefore, the objective of the present study was to investigate any correlation between age-linked serum prostate specific antigen (PSA) levels in normal subjects and patients of benign prostatic hyperplasia and carcinoma prostate.

\section{METHODOLOGY}

The case-control study was approved by the institutional ethics committee at Sindh Institute of Urology and Transplantation (SIUT), Karachi. 250 subjects were enrolled from the out patients department at SIUT and 93 were finally selected, after obtaining informed consent.

Out of 93 subjects selected for the study, 31 each were 
placed in the normal, BPH and CaP groups. Each group was further divided into four sub-groups of ages $40-49,50-59,60-69$ and 70 and above years. Only subjects 40 years of age and above were included. Subjects with any urinary tract disorder and those under treatment with 5-á-reductase inhibitors were excluded. After PSA estimation, diagnosis of $\mathrm{BPH}$ was confirmed by TRUS and $\mathrm{CaP}$ by histopathology.

For PSA estimation, $10 \mathrm{cc}$ venous blood sample from each patient was collected prior to the subject's DRE, to preclude any rise in serum PSA level. Serum was then separated and frozen at $-20^{\circ} \mathrm{C}$, till assayed. The estimation of PSA was done by AxSYM total PSA (tPSA) assay ${ }^{\circledR}$, based on the principle of Microparticle enzyme immunoassay, Abbott Laboratories, USA.

Values in the data were expressed as mean and standard error of mean. Fischer's test, students't test and correlation coefficient were used to determine significance and for comparison of data.

\section{RESULTS}

Table-I shows the total number of cases, their distribution in different groups and the mean PSA concentration \pm standard deviation in the four subgroups (i.e., $40-49,50-59,60-69$, and 70 and above years) of normal, BPH and CaP cases. Mean serum PSA level was $0.56(\mathrm{SD}=0.09) \mathrm{ng} / \mathrm{mL}$ in normals, $1.41(\mathrm{SD}=1.25) \mathrm{ng} / \mathrm{mL}$ in BPH cases and $36.4(\mathrm{SD}=0.56) \mathrm{ng} / \mathrm{mL}$ in CaP cases in 40-49 years sub-group. Mean serum PSA level was 0.63 $(\mathrm{SD}=0.59) \mathrm{ng} / \mathrm{mL}$ in normals, $5.12 \quad(\mathrm{SD}=7.62)$ $\mathrm{ng} / \mathrm{mL}$ in $\mathrm{BPH}$ cases and $1.94(\mathrm{SD}=206.40) \mathrm{ng} / \mathrm{mL}$ in $\mathrm{CaP}$ cases in 50-59 years sub-group. Mean serum PSA level was $0.96(\mathrm{SD}=0.62) \mathrm{ng} / \mathrm{mL}$ in normals, $5.82(\mathrm{SD}=6.61) \mathrm{ng} / \mathrm{mL}$ in BPH cases and 1.20 $(\mathrm{SD}=159.6) \mathrm{ng} / \mathrm{mL}$ in CaP cases in $60-69$ years subgroup. Mean serum PSA level was $0.69(\mathrm{SD}=0.46)$ $\mathrm{ng} / \mathrm{mL}$ in normals, $3.39(\mathrm{SD}=2.03) \mathrm{ng} / \mathrm{mL}$ in $\mathrm{BPH}$ cases and $52.1(\mathrm{SD}=34.59) \mathrm{ng} / \mathrm{mL}$ in CaP cases in 70 and above years sub-group.

Table-II shows the multiple pair-wise comparisons (post-hoc) of PSA levels between the three groups of different sub-groups of age. There was a highly significant difference $(P=0.0001)$ in PSA levels in all groups of 40-49 years sub-group. PSA levels of $\mathrm{CaP}$ were significantly higher in normal as compared to $\mathrm{CaP}(\mathrm{P}=0.001)$ and $\mathrm{BPH}$ as compared to $\mathrm{CaP}$ cases $(p=0.0001)$ but the difference was insignificant in normal versus BPH cases $(p=0.59)$. Highly significant difference $(P=0.001)$ was found in $P S A$ levels in all groups of 50-59 years sub-group. PSA levels of $\mathrm{CaP}$ were significantly higher in normal as compared to $\mathrm{CaP}(\mathrm{P}=0.003)$ and $\mathrm{BPH}$ as compared to

\begin{tabular}{|c|c|c|c|c|c|c|c|}
\hline \multirow[t]{2}{*}{ Age (years) } & \multicolumn{2}{|c|}{ Normal } & \multicolumn{2}{|c|}{ BPH } & \multicolumn{2}{|c|}{ CaP } & \multirow[t]{2}{*}{$\mathbf{P}$} \\
\hline & $n=31$ & PSA (ng/mL) & $n=31$ & PSA (ng/mL) & $n=31$ & PSA (ng/mL) & \\
\hline $40-49$ & 02 & $0.56 \pm 0.09$ & 02 & $1.41 \pm 1.25$ & 02 & $36.40 \pm 0.56$ & $0.0001^{*}$ \\
\hline $50-59$ & 10 & $0.63 \pm 0.59$ & 10 & $5.12 \pm 7.62$ & 09 & $1.94 \pm 206.40$ & $0.001^{*}$ \\
\hline $60-69$ & 10 & $0.96 \pm 0.62$ & 10 & $5.82 \pm 6.61$ & 10 & $1.20 \pm 159.6$ & $0.01 *$ \\
\hline 70 \& above & 09 & $0.69 \pm 0.46$ & 09 & $3.39 \pm 2.03$ & 10 & $52.1 \pm 34.59$ & $0.0001^{*}$ \\
\hline \multicolumn{8}{|c|}{$\begin{array}{l}\text { Table-I. Age-wise serum PSA concentration in normal, BPH and CaP cases - sub group analysis } \\
\text { (The values are expressed as mean } \pm \text { standard deviation) } \\
\qquad P<0.05=\text { Significant }\end{array}$} \\
\hline
\end{tabular}


CaP cases $(p=0.0004)$ but the difference was insignificant in normal versus $\mathrm{BPH}$ cases $(\mathrm{P}=0.99)$. In all groups of 60-69 years sub-group there was a highly significant difference $(P=0.01)$ in PSA levels. PSA levels of $\mathrm{CaP}$ were highly significant in normal as compared to $\mathrm{CaP}(\mathrm{P}=0.01)$ and significant in $\mathrm{BPH}$ as compared to $\mathrm{CaP}$ cases $(p=0.02)$ but the difference was insignificant in normal versus BPH cases $(p=0.99)$. All groups of 70 and above years subgroup have shown a highly significant difference $(P=0.0001)$ in PSA levels. PSA levels of CaP were significantly higher in normal as compared to $\mathrm{CaP}$ $(\mathrm{P}=0.0001)$ and $\mathrm{BPH}$ as compared to $\mathrm{CaP}$ cases $(p=0.0001)$ but the difference was insignificant in normal versus BPH cases $(p=0.95)$.

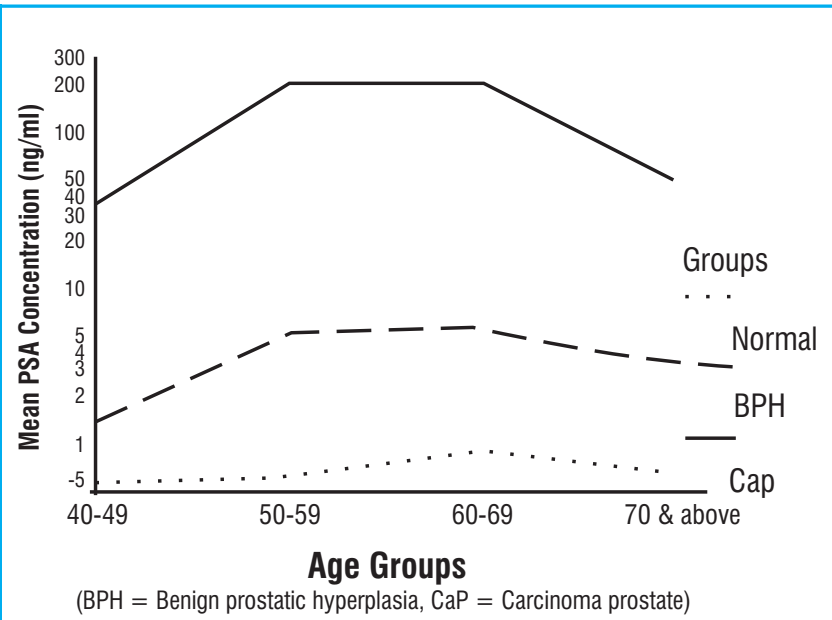

Fig-1. Serum IPSA concentration in different age groups of normal, BPH and CaP patients

\begin{tabular}{|c|c|c|c|c|c|c|}
\hline \multirow{2}{*}{ Age (years) } & \multicolumn{2}{|c|}{ Normal vs. BPH } & \multicolumn{2}{c|}{ Normal vs. CaP } & \multicolumn{2}{c|}{ BPH vs. CaP } \\
\cline { 2 - 7 } & $\begin{array}{c}\text { Mean } \\
\text { Difference }\end{array}$ & P & $\begin{array}{c}\text { Mean } \\
\text { Difference }\end{array}$ & P & $\begin{array}{c}\text { Mean } \\
\text { Difference }\end{array}$ & P \\
\hline $40-49$ & -0.84 & $0.59^{\text {NS }}$ & -35.83 & $0.001^{*}$ & -34.99 & $0.0001^{*}$ \\
\hline $50-59$ & -0.49 & $0.99^{\text {NS }}$ & -193.52 & $0.003^{*}$ & -189.02 & $0.004^{*}$ \\
\hline $60-69$ & -4.85 & $0.99^{\text {NS }}$ & -119.97 & $0.01^{*}$ & -115.12 & $0.02^{*}$ \\
\hline 70 \& above & -2.70 & $0.95^{\text {NS }}$ & -51.46 & $0.0001^{*}$ & -48.76 & $0.0001^{*}$ \\
\hline
\end{tabular}

Table-II. Multiple pair wise comparison of serum PSA concentration in normal, BPH and CaP cases of different ages $N S=$ Non-significant, $\quad * P<0.05=$ Significant

Key: $n=$ Total number of cases, $B P H=$ benign Prostatic Hyperplasia, CaP = Carcinoma Prostate

Regarding the correlation between age and serum PSA levels, overall $(p=0.638)$ as well as within individual groups $(p=0.802$ for normal, $p=0.9$ for $B P H$ and $p$ $=0.331$ for $\mathrm{CaP}$ cases), no significant correlation between age and serum PSA levels was established.

\section{DISCUSSION}

This study, on sub-group analysis of mean serum PSA levels within the normal, BPH and CaP groups, found no significant results. On inter-group comparison of mean serum PSA levels, in normal versus BPH cases, significant difference in $60-69$ years sub-group and highly significant difference in 70 and above years sub-group was observed. On comparison of normal with CaP cases, $40-49$ and 70 and above years subgroups showed highly significant difference, $50-59$ years sub-group showed significant difference and 60 - 69 years sub-group showed no significant difference. When BPH and CaP cases were compared, difference was highly significant in $40-49$ and 70 and above years sub-groups, significant in $50-59$ years sub-group and non-significant in $60-69$ years subgroup.

Our choice of normals in this study was in conformity with many published studies on the subject. Morgan et $\mathrm{al}^{8}$ were similar to the observations in our study, in case of PSA levels of normal cases. Weinrich et al ${ }^{9}$ 
also estimated PSA levels in $40-69$ years age group in white and black men, without considering the presence or absence of prostate disease and their results compare well with results from this study.

Preston et $\mathrm{al}^{10}$ selected healthy subjects (without any history of prostate disease) for their study. The data from their eldest group (age $=40-49$ years) was similar to our study subjects from the $40-49$ years age sub-group. Age specific distribution of serum PSA levels in men aged $40-79$ years, studied by Cooney et $\mathrm{al}^{11}$ compares well with the results of our study. They, however, included individuals without clinically evident prostate disease, in their study.

Although Battikhi' ${ }^{12}$ divided individuals into seven groups at five years interval, unlike the sub-groups in our study, their results match favorably with ours. Kehinde et $\mathrm{al}^{13}$ determined age-specific ranges for serum PSA in men aged $15-79$ years. Their results, when compared with ours, in age sub-groups $40-49$, $60-69$ and $70-79$ years, respectively, show that their PSA values were on a bit lower side than ours.

PSA levels among normal Indian men, evaluated by Chia et $\mathrm{al}^{14}$ were of 50 and above years. Our mean values of PSA were lower than theirs as they have included those who were of 50 and above years age. Our findings, however match with the reference ranges for healthy Korean men between ages 30 to 79 years, studied by Choi et a ${ }^{15}$ in their ranges for $40-49,50$ 59 and $60-69$ years age groups. Like our findings, they reported the highest values in $60-69$ years age group.

Mean PSA levels observed by Mehrabi et $\mathrm{al}^{16}$, when subjects with carcinoma prostate, prostatitis or transurethral instrumentation were excluded, were similar to our results. Results from Collins et $\mathrm{al}^{17}$, however, match with ours in case of BPH cases only, with lower values observed in case of 50-59 and 60 69 years age sub-groups. The reason may be the inclusion of patients above 80 years of age in the study and the bigger sample size, relative to our study.

Roehrborn et $\mathrm{al}^{18}$ have estimated serum PSA values in BPH cases, which resemble our observations, except that they have excluded patients above 80 years and those with serum PSA levels of $>10 \mathrm{ng} / \mathrm{mL}$. Results from Sung et $\mathrm{al}^{19}$ including CaP cases, in $70-80$ years age group, also matched with the results of the same group in our study.

Li et $\mathrm{al}^{20}$ studied 1027 subjects and they found a positive correlation between serum IPSA and age. Their results were different from our study as they considered only men with fifty years of age. Moreover, their serum PSA levels were lower than ours.

Contradictory to our study Bakir et al ${ }^{21}$ found a direct relationship between serum PSA and age in 3,000 healthy Syrian men. However, their serum tPSA levels are much higher than our normals. It could be because of ethnic differences.

Our results do not match with those of Litchfield et $\mathrm{al}^{22}$. Reasons might be the enrollment of 70 and above years' age group in their study. Also prostate cancer cases were not diagnosed

When age was compared with serum PSA levels, in our study, no significant correlation was found. Other studies conducted with similar objectives, demonstrated a mixed trend; from significant correlation $^{8}$ to no significant correlation ${ }^{23}$. As the contradictory studies, were all conducted in the USA, and the study population was not a complete match, the results were not expected to be comparable; due to entirely different racial, climatic, dietary and environmental influences, on the population studied. According to the trend seen in our data, serum PSA levels rise with age, up to a certain age and then decline (graph-1), as observed in cases of 70 and above years sub-group, an unusual finding not 
reported by others. It might be because of decline in testosterone level with age resulting in subsequent rise in estrogen levels which might be resulting in regression of prostate volume and thus in PSA level. To arrive at a definite conclusion about the trends observed, this study may be expanded to include more subjects.

Regarding the limitations of the study, due to time constraint we were unable to include a large number of patients for longer duration. Moreover, not all the patients with carcinoma prostate were willing to participate in the study due to social taboos although they were assured that this information is solely for research purpose and it will not be provided to any third person at any cost.

\section{CONCLUSIONS}

This study found no significant correlation between age-linked serum PSA levels in normal subjects and patients of $\mathrm{BPH}$ and $\mathrm{CaP}$. A trend of rise in PSA levels with increasing age (upto the age of 69 years) followed by declining levels at ages 70 years and above, was however observed.

\section{ACKNOWLEDGMENTS}

This study project was supported by SIUT, Karachi. We are thankful to Professor Dr. S. Adeeb-ul-Hasan Rizvi, Professor Dr. S. A. Anwar Naqvi, Professor Dr. Mirza Naqi Zafar, and all the associated staff at SIUT. We are also grateful to all our study subjects, as without them this study would not have been possible.

\section{Copyright@ 14 Jul, 2012.}

\section{REFERENCES}

1. Zahir N, Mubarik A, Abdullah P, Mehmood A, Zahur-urrehman. Pattern of malignant tumors in Karachi, is it different? J Coll Phys Surg Pak 2000;10:338-41.

2. Gohji K, Nomi M, Kizaki T, Morisue K, Okamoto M, Takenaka $A$, et al. An assessment of the usefulness of serum prostate specific antigen level and cancer volume in biopsy specimen to predict the extent of prostate cancer. Br J Urol 1997;79:602-7.

3. Wang MC, Valenzuela IA, Murphy GP. Purification of a human prostate-specific antigen. Invest Urol 1979:17:159.

4. Kidwai N, Gong Y, Sun X, Deshpande WS, McKinlay JB. Family history and the risk of prostate cancer. Urology 2000;56:803-6.

5. Fakutsu A, Ono Y, Ito M, Yoshino Y, Hattori R, Gotoh M, et al. Relationship between serum prostate specific antigen and calculated epithelial volume. Urology 2003;61:370-74.

6. Vollmer RT, Dawson NA, Vogelzang NJ. The dynamics of prostate specific antigen in hormone refractory prostate carcinoma. An analysis of cancer and leukemia group-B study 9181 of Megestrol acetate. Cancer 1998;83:1989-94.

7. Schmidt JD. Clinical diagnosis of prostate cancer. Cancer 1992;70:S1, 221-24.

8. Morgan To, Jacobsen SJ, McCarthy WF, Jacobson DJ, McLeod DG, Moul JW. Age-specific reference ranges for serum prostate-specific antigen in black men. $\mathrm{N}$ Engl J Med 1996;335:304-10.

9. Weinrich MC, Jacobsen SJ, Weinrich SP, Moul JW, Oesterling JE, Jacobson $\mathrm{D}$, et al. Reference ranges for serum prostate specific antigen in black and white men without cancer. Urology 1998; 52: 967-73.

10. Preston DM, Levin LI, Jacobson DJ, Jacobsen SJ, Rubertone M, Holmes E, et al. Prostate-specific antigen levels in young white and black men 20 to $\mathbf{4 5}$ years old. Urology 2000;56:812-16.

11. Cooney KA, Strawderman MS, Wonjo KJ, Doerr KM, Taylor A, Alcser KH, et al. Age-specific distribution of serum prostate-specific antigen in a community based study of African-American men. Urology 2001;57:91-6.

12. Battikhi MN. Age-specific reference ranges for prostate specific antigen (PSA) in Jordanian patients. Prostate Cancer Prostatic Dis 2003;6(3):25660.

13. Kehinde EO, Mojiminiyi OA, Sheikh M, Al-Awadi KA, 
Daar AS, Al-Hunayan A, et al. Age-specific reference levels of serum prostate-specific antigen and prostate volume in healthy Arab men. BJU Int 2005:3:308-12.

14. Chia SE, Lau Wk, Cheng C, Chin CM, To J, Ho Sh. Prostate-specific antigen levels among Chinese, Malays and Indians in Singapore from a Community based study. Asian Pac J Cancer Prev 2007;8(3):3758.

15. Choi YD, Kang DR, Nam CM, Kim YS, Cho SY, Kim SJ, et al. Age specific prostate specific antigen reference ranges in Korean men. Urology 2007;70(6):1113-6.

16. Mehrabi S, Ghafarian Shirhzii HR, Rassti M. Normal serum prostate specific antigen levels in men in Yasuj province, Islamic Republic of Iran. East Mediterr Health J 2007;13(5):1190-4.

17. Collins GN, Lee RJ, McKelvie GB, Rogers CAN, Hehir M. Relationship between prostate specific antigen, prostate volume and age in benign prostate. $\mathrm{J}$ Urol 1993;71:445-50.

18. Roehrborn CG, Boyle P, Gould AL, Waldstreicher J. Serum prostate specific antigen as a predictor of prostate volume in men with benign prostatic hyperplasia. Urology 1999;53:581-9.
19. Sung JC, Kabalin JN, Terris MK. Prostate cancer detection, characterization, and clinical outcomes in men aged 70 years and older referred for transrectal ultrasound and prostate biopsies. Urology 2000;56:291-301.

20. Li X, Zhang XH, Zhang Z, Li SQ, Lin J; BPC-BPH team. Relationship of age over 50 years and serum prostate specific antigen in men of Beijing multicentre communities. Beijing Da Xue Xue Bao. 2012 Apr 18; 44(2):288-90.

21. Bakir MA, Abo-Daher D. Age-specific reference ranges for prostate-specific antigen among healthy Syrian men. Int J Biol Markers. 2012 May 28:0. doi: 10.5301/JBM.2012.9304. [Epub ahead of print].

22. Litchfield MJ, Cumming RG, Smith DP, Naganathan V, Le Couteur DG, Waite LM, Blyth FM, Handelsman DJ. Prostate-specific antigen levels in men aged 70 years and over: findings from the CHAMP study. Med J Aust 2012; 196(6):395-8

23. De Antoni EP, Crawford ED, Oesterling JE, Ross CA, Berger ER, McLeod DG, Staggers F and Stone NN. Age and race-specific reference ranges for prostratespecific antigen from a large community-based study. Urology 1996; 48: 234-39.

\section{AUTHOR(S):}

1. DR. ZEHRA NAZ, MBBS, M PHIL, FCPS Associate Professor and HOD Biochemistry, Islamic International Medical College (RIU), Rawalpindi, Pakistan.

2. DR. SAADIA ANJUM, MBBS, M Phil

Professor and Chairman of Biochemistry Department Al-Nafees Medical College,

Rawalpindi, Pakistan.

3. DR. MEHDI RAZA, MBBS, M.Sc.

Nuclear Physician,

Armed Forces Institute of Pathology,

Rawalpindi, Pakistan.

\section{Correspondence Address:}

Dr. Zehra Naz

25-A, Lane-3, Tulsa Road, Lalazar Colony,

Rawalpindi, Pakistan.

zehranaz@hotmail.com 